\title{
Article \\ Compensatory Base Changes Reveal Sexual Incompatibility among Members of the Anopheles subpictus Sensu Lato (Diptera: Culicidae) Species Complex in Sri Lanka
}

\author{
D. P. W. Jayatunga ${ }^{1}$ (D) I. N. Harischandra ${ }^{2}\left(\mathbb{D}\right.$, N. V. Chandrasekharan ${ }^{3}$ and B. G. D. N. K. de Silva ${ }^{1,2, *(\mathbb{D})}$ \\ 1 Center for Biotechnology, Department of Zoology, Faculty of Applied Sciences, University of Sri \\ Jayewardenepura, Gangodawila, Nugegoda 10250, Sri Lanka; pamodajayatunga@gmail.com \\ 2 Genetics and Molecular Biology Unit, Faculty of Applied Sciences, University of Sri Jayewardenepura, \\ Gangodawila, Nugegoda 10250, Sri Lanka; iresha@sci.sjp.ac.lk \\ 3 Department of Chemistry, Faculty of Science, University of Colombo, Colombo 00300, Sri Lanka; \\ nchandra@chem.cmb.ac.lk \\ * Correspondence: nissanka@sci.sjp.ac.lk; Tel.: +94-112804515 or +94-774467277
}

\section{check for}

updates

Citation: Jayatunga, D.P.W.; Harischandra, I.N.; Chandrasekharan, N.V.; de Silva, B.G.D.N.K.

Compensatory Base Changes Reveal

Sexual Incompatibility among

Members of the Anopheles subpictus Sensu Lato (Diptera: Culicidae) Species Complex in Sri Lanka. Life 2021, 11, 211. https://doi.org/ $10.3390 /$ life11030211

Academic Editor: Koichiro Tamura

Received: 31 December 2020

Accepted: 2 March 2021

Published: 8 March 2021

Publisher's Note: MDPI stays neutral with regard to jurisdictional claims in published maps and institutional affiliations.

Copyright: (c) 2021 by the authors. Licensee MDPI, Basel, Switzerland. This article is an open access article distributed under the terms and conditions of the Creative Commons Attribution (CC BY) license (https:// creativecommons.org/licenses/by/ $4.0 /)$.

\begin{abstract}
The mosquito Anopheles (Cellia) subpictus sensu lato (s.1.) is a major secondary vector of malaria in Sri Lanka. The sibling species composition in this species complex in Sri Lanka remains debatable. Compensatory base changes (CBCs) in the secondary structures of internal transcribed spacer 2 (ITS2) are reliable sources to predict sexual incompatibility among closely related species. The objective of the present study was to investigate the An. subpictus s.l. populations in Sri Lanka using the CBC analysis. Mosquito DNA was amplified and sequenced for the ITS2 region. The sequences were annotated using ITS2 Database. ITS2 secondary structures were constructed and analyzed for CBCs using various bioinformatics tools. The ITS2 regions consisted of two different lengths, $575 \mathrm{bp}$ and $480 \mathrm{bp}$. The two CBCs and three hemi CBCs identified in the present study suggest that there may be at least two sexually incompatible sibling species. In conclusion, it is likely that there may be only two reproductively isolated sibling species in the An. subpictus species complex in Sri Lanka. However, due to high divergence of ITS2 in these species, it is reasonable to assume that they may be undergoing a speciation event to separate as a distinct species.
\end{abstract}

Keywords: Anopheles subpictus; compensatory base changes (CBCs); internal transcribed spacer 2 (ITS2); ITS2 secondary structures; sibling species

\section{Introduction}

Malaria is a fatal, historical disease in Sri Lanka that is caused by protozoan parasites from the genus Plasmodium. Having a long-documented history of malaria, the country experienced the most devastating epidemics in the period of 1934-1935 [1]. Malaria in Sri Lanka is highly unstable, such that it has historically fluctuated greatly over the years with significant seasonal differences. However, according to the Monitoring and Evaluation plan 2010-2014 of the National Malaria Control Programme of Sri Lanka, the risk of malaria outbreaks has declined dramatically [2]. As a result, Sri Lanka has been certified to be free of malaria, since 2016. However, the risk of disease recurrence on the island does not fade for being a tourist destination for travelers from malaria-endemic countries across the globe [3]. Nearly fifty cases of malaria are annually reported from various parts of the country due to imported malaria [3]; however, failure to promptly detect and treat such cases at early stages poses a serious risk of getting the disease back in the country. The presence of malaria vector mosquitoes throughout the island may be equally responsible for the potential re-emergence of the disease in all parts of the country [4].

Mosquito vectors of malaria, the Anophelines often belong to morphologically similar and reproductively isolated sympatric populations within taxons known as sibling species complexes [5]. In nomenclature, if a member sibling species in a species complex is 
identified and known, the suffix sensu stricto (s.s.) follows the species name. If sibling species status is unknown and a mixture of sibling species exist, the suffix sensu lato (s.l.) follows the species name. Sibling species have different habitats, biting habits and vector competence that result in different vectorial capacities [6]. Therefore, the precise identification of Anopheline mosquito species complexes plays a pivotal role in malaria elimination through vector control [7].

The main vector of malaria in Sri Lanka is Anopheles culicifacies Giles s.l. and Anopheles subpictus Grassi s.l. 1899 is a major secondary vector [8]. Eventhough An. subpictus is considered an important secondary vector of malaria in many parts of Sri Lanka [8], there has been no recent evidence of its Plasmodium transmission [9]. However, the current passive state of malaria in the country can be regarded as a warning towards future resurgences due to important secondary vectors with acquired vectorial capacity. Supportive evidence was indicated by a study conducted in Northern Jaffna district in Sri Lanka, that An. subpictus s.l. had a higher sporozoite rate than An. culicifacies during a peak transmission period [9] and also by the fact that $A n$. subpictus was acting as a known malaria vector in South Asia including nearby India [10].

In India, An. subpictus was first found to be a species complex based on differences in larval morphology [11]. Further, based on two distinct types of eggs and cytological evidence, Reuben and Suguna [12] temporarily designated two forms of An. subpictus sibling species, as $\mathrm{A}$ and $\mathrm{B}$ in India. Later, four sibling species of An. subpictus were identified, namely A, B, C and D, based on morphological and chromosomal characters [13]. The stage-specific morphological characters to identify the siblings A-D are egg float ridge number, fourth instar larval mesothoracic seta IV, pupal seta 7-I and apical pale and pre-apical dark bands in palpi of adults [13]. Furthermore, these sibling species (A-D) were also confirmed through fixed inversions in the $\mathrm{X}$-arm of polytene chromosomes viz. $\mathrm{A}=\mathrm{X}+{ }^{\mathrm{a}},{ }^{+}{ }^{\mathrm{b}}$; species $\mathrm{B}=\mathrm{Xa}, \mathrm{b}$; species $\mathrm{C}=\mathrm{Xa},{ }^{\mathrm{b}}$; species $\mathrm{D}=\mathrm{X}+\mathrm{a}, \mathrm{b}$ [13]. In Sri Lanka, the existence of $A n$. subpictus sibling species $\mathrm{A}$ and $\mathrm{B}$ was first reported based on the single inversion $\left(X+{ }^{a} / X^{a}\right)$ on the $X$ chromosome [14]. All four sibling species $(A-D)$ have been reported in the country based on the previously reported morphometric identification characters [15]. Later, however, variations of morphological characters of An. subpictus sibling species were reported in various parts of the island $[9,16]$. Molecular analyses of internal transcribed spacer 2 (ITS2) and Cytochrome $c$ Oxidase I (COI) have confirmed the presence of only two sibling species of the complex designating them provisionally as $\mathrm{A}$ and B [17]. Moreover, it has been recently reported that there are only two sibling species of An. subpictus in Thailand and more than one species in Indonesia [18]. This study has made use of crossing experiments, from which three distinct clades of COI phylogeny were determined as conspecific [18]. The work of Sindhania et al. [19] also suggests that there are three molecular forms of An. subpictus s.l. in the Indian subcontinent.

Speciation is a significant evolutionary phenomenon that occurs over time giving rise to new biological species $[20,21]$. The separation of members of different species based on genetic differences within sympatric populations occurs via reproductive barriers leading to subsequent reproductive isolation. The most probable reason for the appearance of sibling species or a species complex is the reconstruction of a genotype due to the reproductive isolation of two species that gives rise to mating incompatibility [5,22]. Sibling species are similar in morphology; however, they may accompany subtle morphological differences due to recently accumulated genetic mutations [23]. This state being in the early stages of reproductive isolation, sibling species may be deemed to have mutations in a least number and size of genes/intergenic regions that determines reproductive isolation leading to speciation [24]. These genomic islands of divergence, also known as speciation islands, are resistant to the homogenizing effects of gene flow [24]. For instance, as reported for Anopheles gambiae subtaxa M and S, which later elevated to species status as Anopheles coluzzii and Anopheles gambiae s. s. respectively, speciation islands showed a considerable gene flow [25]. However, it has later been shown that the entire 2L genomic island has undergone introgression during a period of rapid increase of voltage-gated 
sodium channel mutation (Vgsc-1014F), with apparently negligible impact on reproductive isolation [26]. In this respect, multigenic families in eukaryotic genomes may offer an appropriate degree of conservation for identification and inferring relationships among sibling species due to concerted evolution [27]. Ribosomal DNA (rDNA) ITS2 has proven to be an excellent molecular marker in uncovering sibling species, especially at lower taxonomic levels [28-30].

Located between the rRNA genes 5.8S, and 28S, ITS2 plays an important role in rRNA processing. The excision process of the ITS2 in the RNA transcript requires the formation of ITS2 secondary structures which seem to be conserved across most eukaryotes [31]. Further, a universal eukaryotic ITS2 secondary structure indicative of distinct hallmark features, was reported by Schultz et al. [32]. The hallmarks of a core ITS2 secondary structure consists of four helices with the helix III being the longest, a UGGU motif $5^{\prime}$ to the apex (deviations like UGGGU, UGG, or GGU have been described [33]) and a U-U mismatch in the helix II [32]. ITS2 secondary structures have been used for delimiting biological species based on the presence of compensatory base changes (CBCs) in the helix II or III of the structures [34-36]. CBCs occur in a paired region of a primary RNA transcript when both nucleotides of a paired site mutate while the pairing itself is maintained (e.g., G-C mutates to A-U) [37]. Hemi CBCs are transcripts in which only one nucleotide of a paired site mutates while the nucleotide bond is maintained (G-C mutates to AC) [37]. Apparently, hemi CBCs can be regarded as intermediate products leading to CBCs. $\mathrm{CBC}$ are associated with sexual incompatibility that taxa exhibiting at least one $\mathrm{CBC}$ in the conserved regions of the ITS2 secondary structures most likely belong to different biological species $[36,38]$. In fact, if there is one $C B C$, there is a $\sim 0.93$ probability that they belong to two different species [37]. However, since the CBC approach is a oneway tool, the absence of $\mathrm{CBC}$ s does not necessarily rule out that the two strains belong to one species but there is $\sim 0.76$ probability that they are the same species [37]. The occurrence of CBCs can be the underlying reason that ITS2 has appeared to be an effective indicator of species identification, accumulating mutations in reproductively isolated populations [39]. Thus, it has been shown that determining the presence of CBCs in ITS2 rRNA secondary structures is a reliable diagnostic tool of taxon analysis in prokaryotes placozoans [40] as well as higher eukaryotic lineages such as tick Paramacrobiotus [41], Altica beetles [42] and flowering plant Corydalis [43]. Furthermore, CBC analysis has been shown to play a supportive role in uncovering cryptic species in taxa including the marine protist Amoebophrya ceratii [44], marine diatom genus Pseudo-nitzschia [45] and skipper butterfly Urbanus belli [46]. Interestingly, CBC-based reproductive isolation at ITS2 has uncovered nine cryptic species within the mosquito Anopheles longirostris in Papua New Guinea [47].

In this context, it can be suggested that the controversy of the sibling species status of An. subpictus species complex in Sri Lanka may be resolved by predicting the reproductive isolation among its member species. Therefore, the objective of the present study was to analyze the intraspecies status of An. subpictus taxon in Sri Lanka based on ITS2 secondary structures and CBC analysis.

\section{Materials and Methods}

\subsection{Mosquito Sampling}

Wild engorged female mosquitoes were collected $(n=128)$ during 2011-2014, with the assistance of entomological assistants, from five localities in Sri Lanka (Figure 1); Monaragala $\left(6^{\circ} 87^{\prime} 27.02^{\prime \prime} \mathrm{N}, 81^{\circ} 35^{\prime} 06.70^{\prime \prime} \mathrm{E}\right)$, Kurunegala $\left(7^{\circ} 48^{\prime} 71.00^{\prime \prime} \mathrm{N}, 80^{\circ} 36^{\prime} 49.95^{\prime \prime} \mathrm{E}\right)$, Puttalam $\left(8^{\circ} 03^{\prime} 00.57^{\prime \prime} \mathrm{N}, 79^{\circ} 83^{\prime} 11.14^{\prime \prime} \mathrm{E}\right)$, Chilaw $\left(7^{\circ} 57^{\prime} 65.41^{\prime \prime} \mathrm{N}, 79^{\circ} 79^{\prime} 56.57^{\prime \prime} \mathrm{E}\right)$ and Batticaloa $\left(7^{\circ} 72^{\prime} 04.50^{\prime \prime} \mathrm{N}, 81^{\circ} 70^{\prime} 10.86^{\prime \prime} \mathrm{E}\right)$ using Cattle-Baited Hut Collection (CBHC) and Cattle-Baited Net Collection (CBNC) methods. The mosquitoes were identified as An. subpictus using the standard mosquito identification keys [48]. Under laboratory conditions, they were facilitated to lay eggs and the $\mathrm{F}_{1}$ progeny adults were obtained. However, the $F_{1}$ adults were not identified for their sibling species status as described in Suguna et al. [13], due to the morphological polymorphism observed in all life cycle stages. 


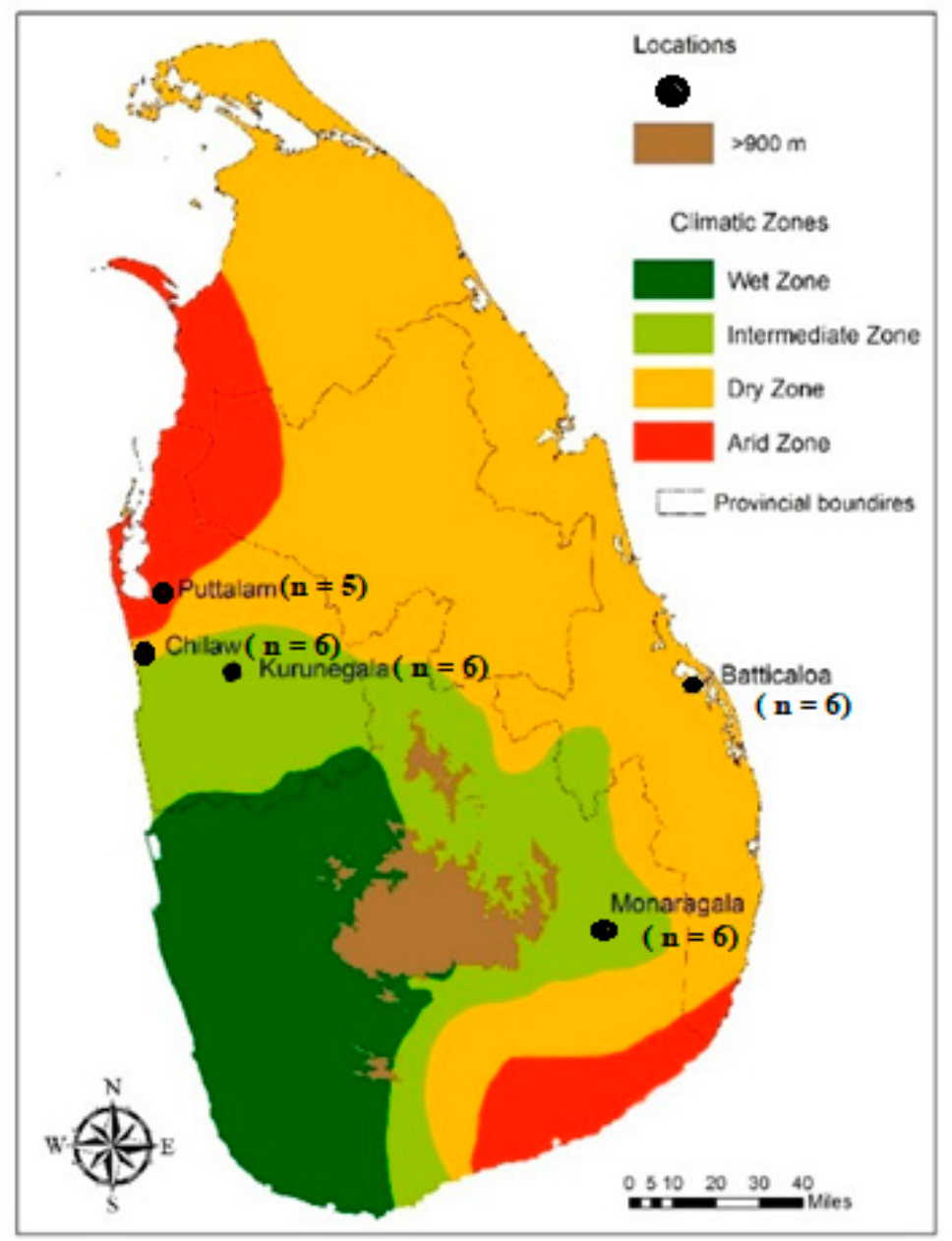

Figure 1. A map of Sri Lanka showing sampling sites: Puttalam, Chilaw, Kurunegala, Batticaloa and Monaragala [12].

As shown in Figure 1, the location-wise distribution of the $F_{1}$ mosquitoes used in the molecular analysis $(n=29)$ encompassed 6 mosquitoes from each of the locations in Monaragala, Kurunegala, Batticaloa, Chilaw and 5 mosquitoes from Puttalam.

\subsection{DNA Extraction and PCR Amplifications}

Genomic DNA of $\mathrm{F}_{1}$ mosquitoes were extracted using a phenol-chloroform extraction method [49]. The ITS2 region was amplified using previously used PCR primers, reaction mixes and thermal profile [16] and sequenced at Macrogen Inc., Seoul, South Korea. The sequences were assembled using DNA Baser Sequence Assembler v3x (2014) and aligned using ClustalW multiple alignment (https://www.genome.jp/tools-bin/clustalw) [50]. An. subpictus ITS2 sequences of the present study were deposited in GenBank (KP165072KP165079).

\subsection{Determination of Genetic Divergence of ITS2}

Genetic polymorphism of ITS2 region was determined in terms of gaps/missing data, GC content, number of haplotypes, haplotype diversity and nucleotide diversity using the software DnaSP v6.12.01 [51]. Additionally, the web server, Spectral Repeat Finder (SRF) [52] was utilized to find ITS2-specific dimers, trimers, tetramers. The program MEGA-X was used in calculating Kimura-2-parameter (K2P) for all ITS2 haplotypes [53]. 


\subsection{ITS2 Sequence Phylogeny}

Phylogenetic analysis was performed for the generated ITS2 sequences (KP165072KP165079) and NCBI-retrieved ITS2 sequences. However, for ITS2, selection of GenBank sequences for phylogeny construction was limited depending on the availability of full ITS2 length. Anopheles annularis was chosen to be the outgroup due to its phylogenetic distance from An. subpictus. Best-suited DNA substitution model was determined as the general time reversible model (GTR), using the programme jModelTest 0.1.1 [54]. ITS2 phylogeny was constructed by Maximum Likelihood (ML) method using MEGA-X with 1000 bootstrap replicates [53]. The estimated bootstrap values were reported as ML bootstrap percentages.

\subsection{ITS2 Sequence-Structure Analysis}

The aligned full-length ITS2 sequences were annotated using Hidden Markov Models (HMMs) [55], implemented in the ITS2 Database (http:/ /its2.bioapps.biozentrum.uniwuerzburg.de/) to determine the proper ITS2 borders. ITS2 secondary structures (Default settings at $37^{\circ} \mathrm{C}$ ) were constructed using the program RNAStructure v5.6 [56]. They were viewed using the program 4SALE v1.5 $[57,58]$ and the minimum free-energy structure that fulfilled the hallmarks of the typical eukaryotic ITS2 secondary structure [36] was selected as the template for custom homology modeling of the other sequences. The ITS2 secondary structures were obtained by homology modeling using the ITS2 Database and were viewed by the program PseudoViewer v 3.0 [59]. Global multiple sequence-structure alignments were automatically generated in 4SALE $[57,58]$, and ITS2 sequences and their respective secondary structures were aligned using a $12 \times 12$ ITS2 sequence-structure specific scoringmatrix. This was used in the ProfDistS v0.9.9 [60] to obtain the ITS2 sequence-structure specific profile neighbor-joining (PNJ) tree.

\subsection{Analysis of Compensatory Base Changes (CBCs)}

The ITS2 sequence-structure data set was further analyzed for the presence of CBCs. CBCs were identified using the CBCAnalyzer option implemented in 4SALE v1.7 [57,58]. Furthermore, the ITS2 secondary structures were manually analyzed and confirmed for the $\mathrm{CBC}$ s and for hemi-CBCs. For comparison purposes, $\mathrm{CBC}$ s were also analyzed for the closely related species, An. subpictus, Anopheles vagus and Anopheles sundaicus using eligible GenBank retrieved sequences (An. subpictus: EF601868, EF601870; An. vagus: FJ457631, FJ654649; An. sundaicus: GQ284824, AY662258, AF369560, AF369562, AF469857, AY662445, GQ480826. The CBC table was transferred from the 4SALE results.

\section{Results}

3.1. Annotation of ITS2 Reveals Two Types of An. subpictus

The ITS2 sequence data of the present study did not contain any ITS2-specific sequence motifs. Table 1 summarizes the ITS2 data which are represented by the GenBank accession numbers KP165072-KP165079. KP165072 represents 15 specimens of the study. The accessions, KP165073-KP165079, represent 14 specimens that gave a nucleotide diversity of 0.00059 . The sequences represented by KP165072 showed a high genetic distance value $(\mathrm{K} 2 \mathrm{P}=0.1)$ with respect to the ITS2 sequences represented by KP165073-KP165079 (Table 2).

Table 1. Overall summary of ITS2 parameters.

\begin{tabular}{ccc}
\hline & & ITS2 \\
\hline Size & $480 \mathrm{bp}$ & $575 \mathrm{bp}$ \\
\hline No. of sequences $(\mathrm{n})$ & 15 & 14 \\
\hline No. of segregating sites, $(\mathrm{S})$ & 0 & 1 \\
\hline No. of haplotypes $(\mathrm{h})$ & 1 & 2 \\
\hline Haplotype diversity $\left(\mathrm{H}_{\mathrm{d}}\right)$ & 0 & 0.263 \\
\hline Nucleotide diversity $(\pi)$ & 0 & 0.00059
\end{tabular}


Table 2. Evolutionary divergence of sequences and the number of CBCs. Lower diagonal: Estimates of evolutionary divergence (K2P) for the study-generated ITS2 sequences; Upper diagonal: number of CBCs among study-generated ITS2 sequences.

\begin{tabular}{cccccccc}
\hline & 1 & 2 & 3 & 4 & 5 & 6 & 7 \\
\hline KP165072 & & 2 & 2 & 2 & 2 & 2 & 2 \\
\hline KP165073 & 0.100 & & 0 & 0 & 0 & 0 & 0 \\
\hline KP165074 & 0.100 & 0.004 & & 0 & 0 & 0 & 0 \\
\hline KP165075 & 0.098 & 0.004 & 0.004 & & 0 & 0 & 0 \\
\hline KP165076 & 0.098 & 0.003 & 0.004 & 0.002 & & 0 & 0 \\
\hline KP165077 & 0.100 & 0.005 & 0.002 & 0.004 & 0.002 & & 0 \\
\hline KP165078 & 0.098 & 0.005 & 0.002 & 0.004 & 0.002 & 0.000 & \\
\hline KP165079 & 0.098 & 0.002 & 0.002 & 0.002 & 0.000 & 0.000 & 0.000 \\
\hline
\end{tabular}

\subsection{ITS2 Secondary Structures Reveal Complimentary Base Changes}

Two representative ITS2 secondary structures were derived for An. subpictus specimens in the present study (Figures 2 and 3). The structures were visibly different to each other in branching at the tip of helix III. The CBC analysis identified two CBCs (1. U-A to G-C; 2. A-U to G-C) and three hemi CBCs (1. G-U to A-U; 2. G-U to A-U; 3. A-U to G-U) in the helix III.

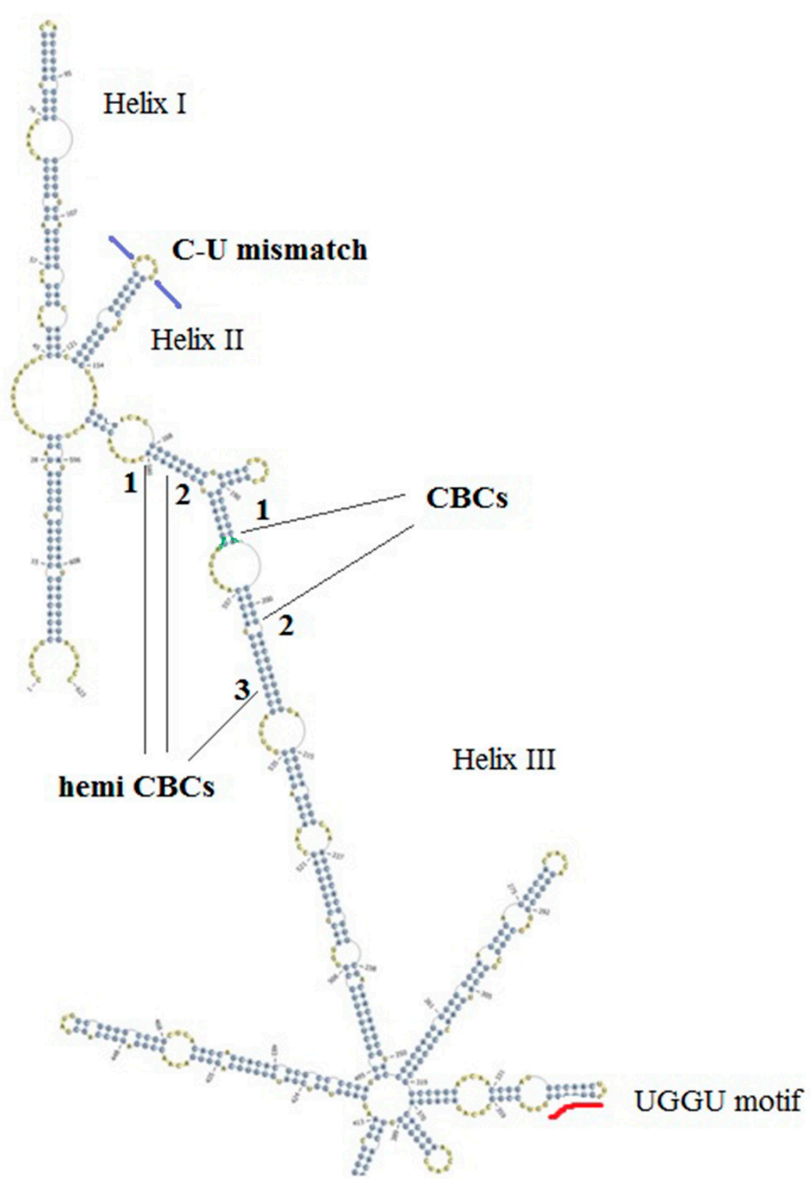

Figure 2. Three helix ITS2 secondary structure representing the $575 \mathrm{bp}$ sized ITS2 sequences in the study. C-U mismatch is shown in helix II and a UGGU motif included in the distal part of helix III. Two compensatory base changes and the three hemi compensatory base changes are shown in numbers. 


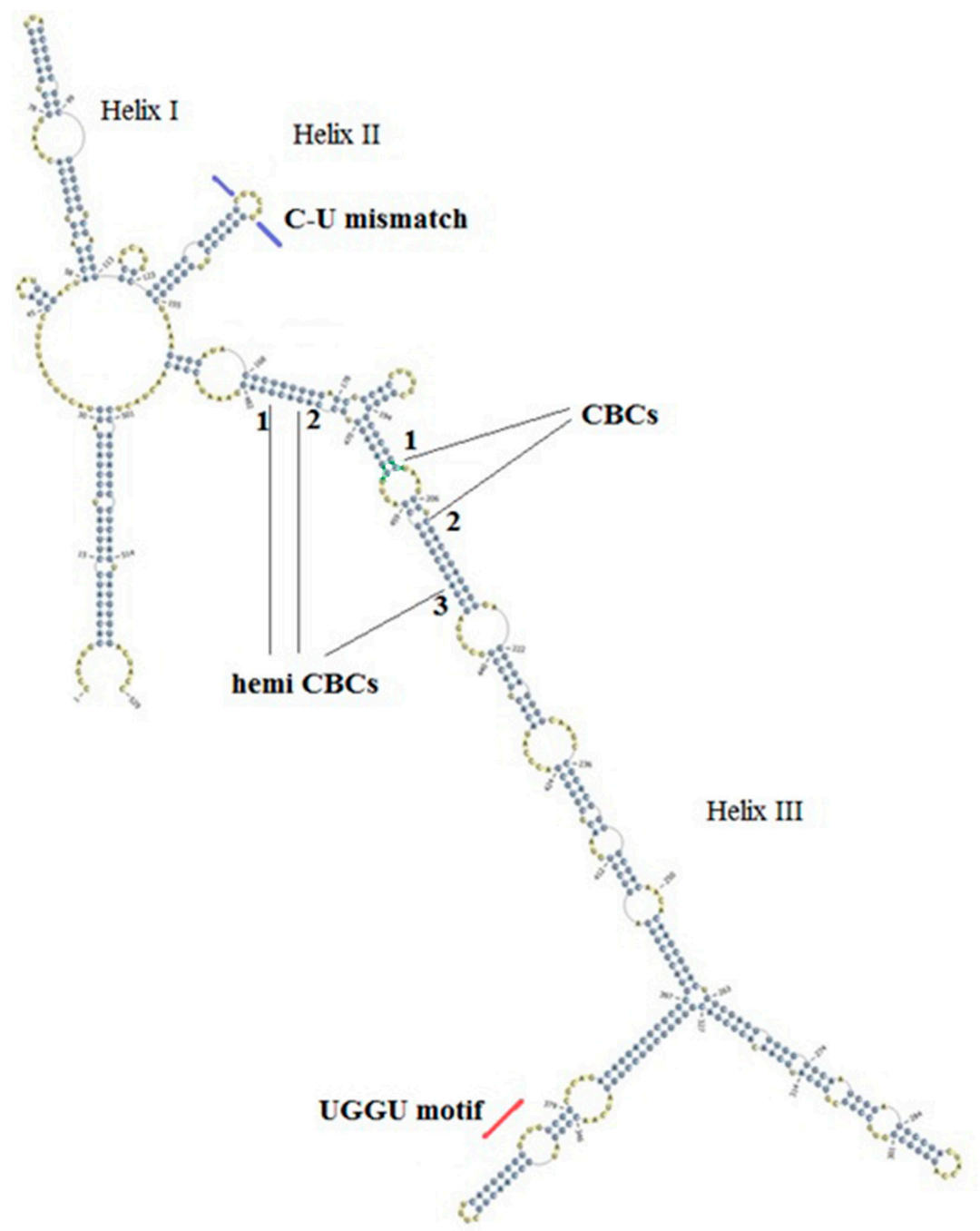

Figure 3. Three helix ITS2 secondary structure representing the $480 \mathrm{bp}$ sized ITS2 sequences in the study. C-U mismatch is shown in helix II and a UGGU motif included in the distal part of the helix III. Two compensatory base changes and the three hemi compensatory base changes are shown in numbers.

The number of CBCs detected against each ITS2 haplotype in the study are indicated in the upper diagonal of Table 2. For comparison purposes, $\mathrm{CBC}$ analysis among the closely related species is shown in Table 3. The presence of one or more CBCs between any two species imply that they are reproductively isolated, thus belonging to two species.

Despite the single haplotype corresponding to An. subpictus B (KP165072), the many haplotypes corresponding to An. subpictus A (KP165073-KP165079) showed slight differences in the secondary structures, in the branching pattern in helix III, however, CBCs were not detected within those structural changes. 
Table 3. Matrix indicating compensatory base changes (CBCs) of closely related Anopheline species, Anopheles subpictus, Anopheles vagus and Anopheles sundaicus.

\begin{tabular}{|c|c|c|c|c|c|c|c|c|c|c|c|c|c|c|c|}
\hline & & \multicolumn{2}{|c|}{ An. subpictus } & \multirow{2}{*}{$\begin{array}{l}\text { EF601868- } \\
\text { An. } \\
\text { subpictus- } \\
\text { India }\end{array}$} & \multirow{2}{*}{$\begin{array}{l}\text { EF601870- } \\
\text { An.. } \\
\text { subpictus } \\
\text { India }\end{array}$} & \multirow{2}{*}{$\begin{array}{c}\text { FJ457631- } \\
\text { An. vagus } \\
\text { China }\end{array}$} & \multirow{2}{*}{$\begin{array}{c}\text { FJ654649- } \\
\text { An. } \\
\text { vagus- } \\
\text { Indonesia }\end{array}$} & \multirow{2}{*}{$\begin{array}{l}\text { AY662258- } \\
\text { An. } \\
\text { sundaicus- } \\
\text { Malaysia }\end{array}$} & \multirow{2}{*}{$\begin{array}{l}\text { GQ480826- } \\
\text { An. } \\
\text { sundaicus-E. } \\
\text { Timor }\end{array}$} & \multirow{2}{*}{$\begin{array}{l}\text { AF469857- } \\
\text { An. } \\
\text { sundaicus- } \\
\text { Thailand }\end{array}$} & \multirow{2}{*}{$\begin{array}{l}\text { AY662445- } \\
\text { An. } \\
\text { epiroticus- } \\
\text { Vietnam }\end{array}$} & \multirow{2}{*}{$\begin{array}{l}\text { GQ284824- } \\
\text { An. } \\
\text { sundaicus- } \\
\text { Indonesia }\end{array}$} & \multirow{2}{*}{$\begin{array}{l}\text { GQ480823- } \\
\text { An. vagus- } \\
\text { China }\end{array}$} & \multirow{2}{*}{$\begin{array}{c}\text { AF369562- } \\
\text { An. } \\
\text { sundaicus- } \\
\text { Malaysia }\end{array}$} & \multirow{2}{*}{$\begin{array}{l}\text { AF369560- } \\
\text { An. } \\
\text { sundaicus } \\
\text { Malaysia }\end{array}$} \\
\hline & & $\begin{array}{c}\text { ITS2 } \\
575 \mathrm{bp}\end{array}$ & $\begin{array}{c}\text { ITS2 } \\
480 \mathrm{bp}\end{array}$ & & & & & & & & & & & & \\
\hline \multirow{2}{*}{$\begin{array}{c}\text { An. } \\
\text { subpictus } \\
\text { (Present } \\
\text { study) }\end{array}$} & $\begin{array}{l}\text { ITS2 } 575 \\
\text { bp (A) }\end{array}$ & - & 2 & 0 & 0 & 1 & 1 & 2 & 2 & 2 & 2 & 2 & 2 & 2 & 2 \\
\hline & $\begin{array}{l}\text { ITS2 } 480 \\
\text { bp (B) }\end{array}$ & 2 & - & 2 & 2 & 1 & 1 & 0 & 0 & 0 & 0 & 0 & 0 & 0 & 0 \\
\hline \multicolumn{2}{|c|}{$\begin{array}{c}\text { EF601868-An. } \\
\text { subpictus-India }\end{array}$} & 0 & 2 & - & 0 & 1 & 1 & 2 & 2 & 2 & 2 & 2 & 2 & 2 & 2 \\
\hline \multicolumn{2}{|c|}{$\begin{array}{c}\text { EF601870-An. } \\
\text { subpictus-India }\end{array}$} & 0 & 2 & 0 & - & 1 & 1 & 2 & 2 & 2 & 2 & 2 & 2 & 2 & 2 \\
\hline \multicolumn{2}{|c|}{$\begin{array}{c}\text { FJ457631-An. vagus- } \\
\text { China }\end{array}$} & 1 & 1 & 1 & 1 & - & 0 & 1 & 1 & 1 & 1 & 1 & 1 & 1 & 1 \\
\hline \multicolumn{2}{|c|}{$\begin{array}{c}\text { FJ654649-An. } \\
\text { vagus-Indonesia }\end{array}$} & 1 & 1 & 1 & 1 & 0 & - & 1 & 1 & 1 & 1 & 1 & 1 & 1 & 1 \\
\hline \multicolumn{2}{|c|}{$\begin{array}{l}\text { AY662258-An. sundaicus- } \\
\text { Malaysia }\end{array}$} & 2 & 0 & 2 & 2 & 1 & 1 & - & 0 & 0 & 0 & 0 & 0 & 0 & 0 \\
\hline \multicolumn{2}{|c|}{$\begin{array}{c}\text { GQ480826-An. } \\
\text { Sundaicus-E. Timor }\end{array}$} & 2 & 0 & 2 & 2 & 1 & 1 & 0 & - & 0 & 0 & 0 & 0 & 0 & 0 \\
\hline \multicolumn{2}{|c|}{$\begin{array}{l}\text { AF469857-An. } \\
\text { sundaicus-Thailand }\end{array}$} & 2 & 0 & 2 & 2 & 1 & 1 & 0 & 0 & - & 0 & 0 & 0 & 0 & 0 \\
\hline \multicolumn{2}{|c|}{$\begin{array}{l}\text { GQ284824- An. sundaicus- } \\
\text { Indonesia }\end{array}$} & 2 & 0 & 2 & 2 & 1 & 1 & 0 & 0 & 0 & 0 & - & 0 & 0 & 0 \\
\hline \multicolumn{2}{|c|}{$\begin{array}{l}\text { GQ480823-An. vagus- } \\
\text { China }\end{array}$} & 2 & 0 & 2 & 2 & 1 & 1 & 0 & 0 & 0 & 0 & 0 & - & 0 & 0 \\
\hline \multicolumn{2}{|c|}{$\begin{array}{c}\text { AF369562- An. sundaicus- } \\
\text { Malaysia }\end{array}$} & 2 & 0 & 2 & 2 & 1 & 1 & 0 & 0 & 0 & 0 & 0 & 0 & - & 0 \\
\hline \multicolumn{2}{|c|}{$\begin{array}{l}\text { AF369560- An. sundaicus- } \\
\text { Malaysia }\end{array}$} & 2 & 0 & 2 & 2 & 1 & 1 & 0 & 0 & 0 & 0 & 0 & 0 & 0 & - \\
\hline
\end{tabular}


3.3. ITS2 Sequence-Structure Analysis and ITS2 Sequence Phylogeny Reveal Two Distinct Clades for An. subpictus s.l.

Unlike neighbor joining which uses a distance-matrix for tree-building, profile-based neighbor joining relies on profiles in the form of sequence-structure alignments. Despite the minimal branch support, PNJ tree of the present study separated the An. subpictus sequences into two different clades (Figure 4).

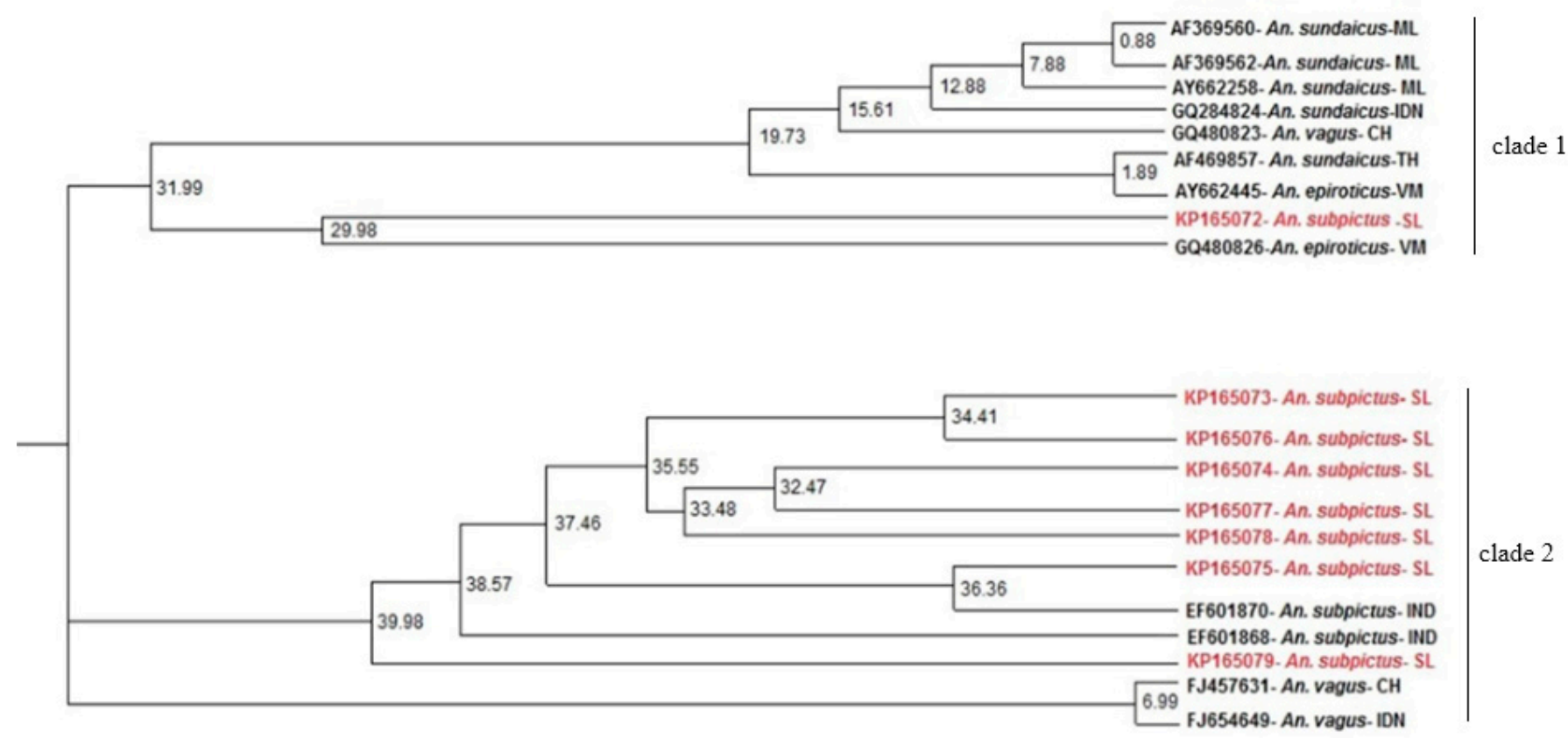

Figure 4. Profile neighbor joining tree for the study generated ITS2 sequence -structures constructed using ProfDistS 0.9.9. for the study-generated ITS2 sequences (KP165072-KP165079). Sequences retrieved from NCBI GenBank: AF369560, AF369562, AY662258-Anopheles sundaicus from Malaysia, GQ284824-An. sundaicus from Indonesia, GQ480823, FJ457631-Anopheles vagus from China, AF469857-An. sundaicus from Thailand, AY662445-Anopheles epiroticus from Vietnam, GQ480826-An. sundaicus from East Timor, EF601870, EF601868-Anopheles subpictus from India, FJ654649_An. vagus from Indonesia, and KC191825 and KC191826-An. subpictus A and B from Sri Lanka were included in the analysis.

The ITS2 phylogenetic tree generated using ML method (Figure 5) also consisted of a similar tree topology to PNJ tree with the An. subpictus sequences dispersed into two different clades. In the ML tree, there is maximum support (bootstrap value 100) for the presence of these two clades. The sequence KP165072 clusters in the same clade 1 with the previously reported An. subpictus B in Sri Lanka (KC191826). Hence, it can be assumed that KP165072 (or clade 1 in the Figure 3) represents An. subpictus B in Sri Lanka. On the other hand, the sequences KP165073-KP165079 can be deemed to be ITS2 variants of $A n$. subpictus A in Sri Lanka due to inclusion in the same clade 2 with the previously reported An. subpictus A (KC191825). Moreover, as shown by the clade 1 in phylogenetic trees (Figures 2 and 3), An. subpictus B is related to An. sundaicus species. However, An. subpictus $\mathrm{A}$ is indicated as very distantly related to An. subpictus $\mathrm{B}$. 


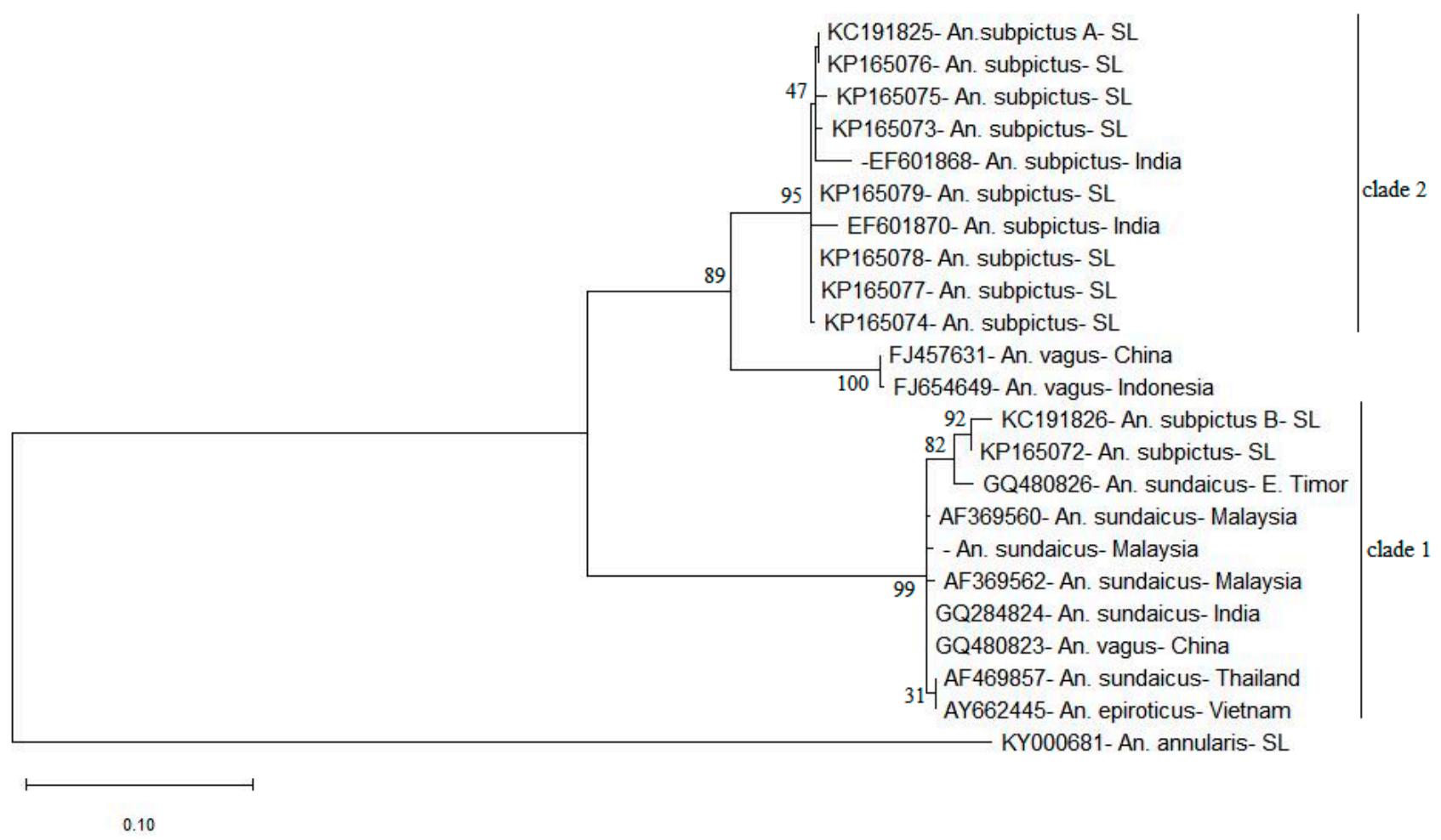

Figure 5. Maximum likelihood phylogenetic tree for study generated ITS2 sequences constructed using MEGA-X for 1000 bootstrap replicates. (Numbers at the nodes indicate bootstrap values). Anopheles annularis sequence (KY000681) served as the outgroup. Sequences retrieved from NCBI GenBank: AF369560, AF369562, AY662258-Anopheles sundaicus from Malaysia, GQ284824-An. sundaicus from Indonesia, GQ480823, FJ457631-Anopheles vagus from China, AF469857An. sundaicus from Thailand, AY662445-Anopheles epiroticus from Vietnam, GQ480826-An. sundaicus from East Timor, EF601870, EF601868-Anopheles subpictus from India, FJ654649-An. vagus from Indonesia and KC191825, and KC191826An. subpictus A and B from Sri Lanka were included in the analysis.

\section{Discussion}

Being a secondary vector of malaria, An. subpictus is a potential key role player in possible future malarial episodes in Sri Lanka. In that regard, precise identification of sibling species in An. subpictus species complex plays a pivotal role in malaria elimination due to distinct variations in the biological characteristics such as vector competence [9]. However, sibling species status of An. subpictus species complex in the country remains controversial $[14,15,17]$. The present study provides a comprehensive molecular characterization of the ITS2 region of An. subpictus s.l. population in Sri Lanka. The ITS2 region was reliably recognized from the ITS2 Database as the 5.8S-28S proximal stem was conserved in all the sequences. Annotation of sequences by the HMM tool available in ITS2 Database indicated that the analyzed ITS2 regions were free of pseudogenes [61]. Determination of reliable borders for ITS2 through $5.8 \mathrm{~S}$ and $28 \mathrm{~S}$ flanking motifs confirmed two different ITS2 lengths for the specimens; $575 \mathrm{bp}$ and $480 \mathrm{bp}$. However, the approximately $100 \mathrm{bp}$ length difference revealed during ITS2 sequence annotation was not noticeable in PCR amplicons (data not shown) due to the reduced resolution of the $0.7 \%$ agarose gel used. The sequence conservation of form B, relative to A, with a nucleotide diversity of 0.00059 and a relatively high genetic distance $(\mathrm{K} 2 \mathrm{P}=0.1)$ clearly shows the genetic divergence of sequences that may have resulted due to different evolutionary constraints.

It has been reported in certain mosquito species, that longer ITS2 regions, as in the case with An. subpictus form A sequences in the present study, are due to occurrence of microsatellites, dimer, trimer, tetramer and pentamer repeats, polynucleotide microsatellites or typical CT repeats in 3' end [62]. However, none was detected in any sequence of the current study. Conversely, sequences of longer ITS2 encompassed many deletions than 
the sequences with shorter ITS2, revealing a positive correlation between the occurrence of deletions and the spacer length.

Furthermore, the present study denies the previous finding that An. subpictus species B was present only in coastal localities of the island [14]. Additionally, found in the present study, record of both An. subpictus sibling species A and B from all the five locations of mosquito collection sites (data not shown) suggests the sympatric nature of the An. subpictus species complex in Sri Lanka.

The ITS2 secondary structures derived in this study fulfilled the characteristic features of the universal eukaryotic ITS2 secondary structure [33]. However, they made only three helices as accordingly for mosquitoes [36] and the structures were congruent with the previously reported Anopheles culicifacies ITS2 secondary structures [63]. Of note is that the ITS2 secondary structures generated in the present study for both A and B sibling species were highly distinct from each other confirming the genetic distance suggested by the ITS2 sequence data. Altogether, both sequence and structure-based disparities indicate decreased introgression between the two sibling species, A and B.

However, this distantly related nature of An. subpictus A and B in Sri Lanka poses a question on their sibling species status whether they are siblings, despite the similar morphology.

The presence of one or more CBCs in ITS2 secondary structures denotes sexual incompatibility and hence, it is an emerging tool for species delineation [38]. The presence of one $\mathrm{CBC}$ suggests that there is $\sim 0.93$ probability that there are two species [37]. Two CBCs and three hemi CBCs between the two types of ITS2 secondary structures in the present study suggest that the sibling species A and B are sexually incompatible. Although the $575 \mathrm{bp}$ sized haplotypes (KP165073-KP165079), showed slight differences in the branching pattern in helix III (results not shown), the absence of CBCs suggest that there is approximately 0.76 probability that they belong to the same species [37] or sibling species.

The phylogenetic analyses of the present study are consistent with the previous studies conducted for ITS2 [15], D3 [15] and COI [17], which clearly separated the species into two clades. Having had a sibling species status transiently updated from two to four within three decades, the present study confirms that the An. subpictus species complex in Sri Lanka is composed of two genetically distinct and sexually incompatible sibling species $\mathrm{A}$ and $\mathrm{B}$. However, the genetic distance between the two $(\mathrm{K} 2 \mathrm{P}=0.1)$ can be considered 'large' at the sibling species level. In this context, it can be inferred that An. subpictus species complex consists of two sibling species A and B; however, with time, they are undergoing a significant evolutionary phenomenon which may lead to potential elevation as a distinct species. This idea is also consistent with our previous findings of intraspecific morphological variations at all life cycle stages [16], indicating an evolutionary process of morphological changes within sibling species. Additionally, considering the earlier characterizations of the complex, the four sibling species A-D [13], changing into two possible sibling species A-B [17], it is reasonable to assume an ongoing speciation process for the complex which may lead to evolution of a new species on the evolutionary time scale.

Discrepancy on the Molecular Taxonomy of Anopheles subpictus, Anopheles sundaicus and Anopheles pseudosundaicus

The taxonomic status of An. subpictus has a complicated history. As reported in 1966, the then subspecies Indefinitus separated from Subpictus as a distinct species, namely Anopheles indefinitus [11]. The species An. subpictus, An. sundaicus and An. vagus belong to Pyretophorus Series. It has been shown that the species An. vagus, An. indefinitus, An. subpictus and An. sundaicus are hard to discriminate based on morphological characters [11]. Moreover, studies initiated after the Tsunami disaster in 2004 have revealed a new mosquito species, Anopheles pseudosundaicus in Southwestern India [64]. This species is also reported to have overlapped morphological characters with the An. subpictus s.l. and is taxonomically close to An. subpictus and An. sundaicus [64]. However, no molecular data have been published to date for An. pseudosundaicus. 
An. sundaicus s.l. is an important vector of malaria in islands and coastal areas of Southeast Asia [65], but it has never been identified to occur in Sri Lanka so far. However, according to Surendran et al. [15], analysis of sequences of the ITS2 and D3 domain of rDNA have suggested that a majority that were identified morphologically as An. subpictus species B in the East coast of Sri Lanka were in fact the members of the Sundaicus complex based on genetic similarity to An. sundaicus s.l. [15]. The ITS2 phylogeny (ML) of the present study illustrated different clades for An. subpictus and An. sundaicus placed in close proximity (Figure 5). This was an evidence for the denial of the concept of genetic similarity of An. subpictus $\mathrm{B}$ and An. sundaicus but it indeed indicated close genetic affinity of $A n$. vagus to An. subpictus $\mathrm{A}$ and $A n$. sundaicus to An. subpictus B.

The $C B C$ analysis indicated that there were no CBCs between Sri Lankan An. subpictus species B and An. sundaicus sequences analyzed (Table 3). Even though there is high chance ( $\mathrm{P}=\sim 0.76)$ that they belong to the same species, theoretically [37], this may not apply here as An. sundaicus is morphologically different to An. subpictus due to presence of speckling, i.e., black and white scaled regions alternatively occurred in legs [65].

Additionally, ITS2 sequence comparison with sequences published by Wilai et al. [18] imply that An. subpictus s.l. in Thailand and Indonesia were distinct but genetically more related to An. subpictus sibling B in Sri Lanka [14] (Multiple sequence alignment shown in Figure S1). Considering this relativity of sibling B and the isolation of sibling A in the clade 2 of the ML tree (Figure 5), sibling A qualifies for potential separation as a distinct species. On the other hand, the $\mathrm{CBC}$ analysis revealed $\mathrm{CBC}$ s between An. subpictus sibling B and An. subpictus in India, suggesting that their reproductive isolation, hence, potential separation as a distinct species. However, further studies are required to confirm this speculation.

\section{Conclusions}

The sibling species composition of An. subpictus species complex in Sri Lanka has undergone significant updates since 1996. However, the present study confirms the early studies by Abhayawardana et al. [14] that An. subpictus s.l. in Sri Lanka is composed of two sibling species A and B. The presence of CBCs in their ITS2 secondary structures corroborate that they are two sexually incompatible species. The highly divergent ITS2 secondary structures also suggest that A and B are highly divergent from each other, thus they may be undergoing a speciation event to separate as a distinct species. However, this notion warrants further investigation in terms of analyzing more DNA loci including mitochondrial markers and single-copy DNA markers. Moreover, it is recommended to examine this mosquito complex for morphological, genomic and ecological variations and speciation information at different time points which may span from years to decades, to observe the outcome of the potential evolutionary processes ongoing with the species complex.

Supplementary Materials: The following are available online at https://www.mdpi.com/2075-1 729/11/3/211/s1, Figure S1: Multiple sequence alignment of An. subpictus s.l. ITS2 sequences generated from the present study and the work by Wilai et al. [18].

Author Contributions: Conceptualization, B.G.D.N.K.d.S. and N.V.C.; methodology, D.P.W.J.; formal analysis, D.P.W.J.; investigation, B.G.D.N.K.d.S., D.P.W.J. and I.N.H.; writing-original draft preparation, D.P.W.J. and I.N.H.; writing-review and editing, D.P.W.J., I.N.H. and B.G.D.N.K.d.S.; supervision, B.G.D.N.K.d.S. and N.V.C. All authors have read and agreed to the published version of the manuscript.

Funding: This research was funded by the University of Sri Jayewardenepura, Sri Lanka, grant number (ASP/06/SCI/RE/2010/18).

Acknowledgments: The authors wish to thank Anti-Malaria Campaign Sri Lanka and the Tropical and Environmental Disease and Health Associates (Pvt.) Ltd. (TEDHA), Sri Lanka for providing mosquito samples.

Conflicts of Interest: The authors declare no conflict of interest. 


\section{References}

1. Wickramasinghe, M.B. Malaria and its control in Sri Lanka. Ceylon Med. J. 1981, 26, 107-115. [PubMed]

2. Abeyasinghe, R.R.; Galappaththy, G.N.L.; Gueye, C.S.; Kahn, F.G.; Feachem, R.G.A. Malaria Control and Elimination in Sri Lanka: Documenting Progress and Success Factors in a Conflict Setting. PLoS ONE 2012, 7. [CrossRef] [PubMed]

3. Antimalarial Campaign, Sri Lanka. Available online: http://www.malariacampaign.gov.lk/index.php/en/ (accessed on 31 October 2018).

4. Weeraratne, T.C.; Surendran, S.N.; Reimer, L.J.; Wondji, C.S.; Perera, M.D.B.; Walton, C.; Karunaratne, S.H.P.P. Molecular characterization of Anopheline (Diptera: Culicidae) mosquitoes from eight geographical locations of Sri Lanka. Malar J. 2017, 16. [CrossRef]

5. Steyskal, G.C. The meaning of the term "sibling species". Syst. Biol. 1972, 21. [CrossRef]

6. Tripathy, A.; Samanta, L.; Das, S.; Parida1, S.K.; Marai, N.; Hazra, R.K.; Kar, S.K.; Mahapatra, N. Distribution of sibling species of Anopheles culicifacies s.l. and Anopheles fluviatilis s.l. and their vectorial capacity in eight different malaria endemic districts of Orissa, India. Mem. Inst. Oswaldo Cruz Rio de Janeiro 2010, 105, 981-987. [CrossRef]

7. Karunaweera, N.D.; Galappaththy, G.N.L.; Wirth, G.F. On the road to eliminate malaria in Sri Lanka: Lessons from history, challenges, gaps in knowledge and research needs. Malar J. 2014, 13. [CrossRef] [PubMed]

8. Amerasinghe, P.H.; Amerasinghe, F.P.; Wirtz, R.A.; Indrajith, N.G.; Somapala, W.; Pereira, L.R.; Rathnayake, A.M. Malaria transmission by Anopheles subpictus (Diptera: Culicidae) in a New Irrigation Project in Sri Lanka. J. Med. Entomol. 1992, 29, 577-581. [CrossRef]

9. Jude P., J.; Ramasamy, R.; Surendran, S.N. Bionomic aspects of the Anopheles subpictus species complex in Sri Lanka. J. Insect Sci. 2014, 14. [CrossRef]

10. Panicker, K.N.; GeethaBai, M.; Rao, B.U.S.; Wiswam, K.; Suryanarayanamurthy, U. Anopheles subpictus vector of malaria in coastal villages of South-East India. Curr. Sci. 1981, 50, 694-695.

11. Reid, J.A. A Note on Anopheles subpictus Grassi and Anopheles indefinitus Ludlow (Diptera: Culicidae). J. Med. Entomol. 1966, 3 , 327-331. [CrossRef]

12. Reuben, R.; Suguna, S.G. Morphological differences between sibling species of the taxon Anopheles subpictus Grassi in India, with notes on relationships with known forms. Mosq. Syst. 1983, 15, 117-126.

13. Suguna, S.G.; Rathinam, G.K.; Rajavel, A.R.; Dhanda, V. Morphological and chromosomal descriptions of new species in the Anopheles subpictus complex. Med. Vet. Entomol. 1994, 8, 88-94. [CrossRef]

14. Abhayawardana, T.A.; Wijesuriya, S.R.G.; Dilrukshi, R.K.C. Anopheles subpictus Complex: Distribution of Sibling species in Sri Lanka. Indian J. Malariol 1996, 33, 53-60.

15. Surendran, S.N.; Singh, O.P.; Jude, P.J.; Ramasamy, R. Genetic evidence for malaria vectors of the Anopheles sundaicus complex in Sri Lanka with morphological characteristics attributed to Anopheles subpictus species B. Malar J. 2010, 9. [CrossRef]

16. Jayatunga, D.P.W.; Harischandra, I.N.; Chandrasekharan, N.V.; de Silva, B.G.D.N.K. Alterations and interchange of morphometric characteristics in different life cycle stages wit reference to the genomic variations of Anopheles subpictus (Diptera; Culicidae) sibling species complex in Sri Lanka. Insects 2018, 9, 89. [CrossRef] [PubMed]

17. Surendan, S.N.; Sarma, D.K.; Jude, P.J.; Kemppainen, P.; Kanthakumaran, N.; Gajapathy, K.; Peiris, L.B.S.; Ramasamy, R.; Walton, C. Molecular characterization and identification of members of the Anopheles subpictus complex in Sri Lanka. Malar J. 2013, 12. [CrossRef]

18. Wilai, P.; Ali, R.S.M.; Saingamsook, J.; Saeung, A.; Junkum, A.; Walton, C.; Harbach, R.E.; Somboon, P. Integrated systematics of Anopheles subpictus (Diptera: Culicidae) in the Oriental Region, with emphasis on forms in Thailand and Sulawesi, Indonesia. Acta Trop. 2020, 208, 1-8. [CrossRef]

19. Sindhania, A.; Das, M.K.; Sharma, G.; Surendran, S.N.; Kaushal, B.R.; Lohani, H.P.; Singh, O.P. Molecular forms of Anopheles subpictus and Anopheles sundaicus in the Indian subcontinent. Malar J. 2020, 19. [CrossRef]

20. Barraclough, T.G.; Nee, S. Phylogenetics and speciation. Trends Ecol Evol 2001, 16, 391-399. [CrossRef]

21. Singh, B.N. Concepts of species and modes of speciation. Curr. Sci. 2012, 103, 784-790.

22. Collins, F.H.; Paskewitz, M. A review of the use of ribosomal DNA (rDNA) to differentiate among cryptic Anopheles species. Insect Mol. Biol. 1996, 5, 1-9. [CrossRef] [PubMed]

23. Frankel, N.; Davis, G.K.; Vargas, D.; Wang, S.; Payre, F.; Stern, D.L. Phenotypic robustness conferred by apparently redundant transcriptional enhancers. Nature 2010, 466, 490-493. [CrossRef] [PubMed]

24. Nosil, P.; Feder, J.L. Widespread yet heterogeneous genomic divergence. Mol. Ecol. 2012, 21, 2829-2832. [CrossRef]

25. Turner, T.L.; Hahn, M.W.; Nuzhdin, S.V. Genomic Islands of Speciation in Anopheles gambiae. PLoS Biol. 2005, 3, e285. [CrossRef]

26. Clarkson, C.S.; Weetman, D.; Essandoh, J.; Yawson, A.E.; Maslen, G.; Manske, M.; Field, S.G.; Webster, M.; Antão, T.; MacInnis, B.; et al. Adaptive introgression between Anopheles sibling species eliminates a major genomic island but not reproductive isolation. Nat. Commun. 2014, 5. [CrossRef]

27. Nei, M.; Rooney, A.P. Concerted and birth-and-death evolution of multigene families. Annu. Rev. Genet. 2005, 39, 121-152. [CrossRef]

28. Dezfouli, S.R.N.; Oshaghi, M.A.; Vatandoost, H.; Assmar, M. rDNA-ITS2 based species-diagnostic Polymerase Chain Reaction assay for identification of sibling species of Anopheles fluviatilis in Iran. Southeast Asian J. Trop. Med. Public Health 2003, 34, 56-60. 
29. Li, C.; Wilkerson, R.C. Intragenomic rDNA ITS2 variation in the neotropical Anopheles (Nyssorhynchus) albitarsis complex (Diptera: Culicidae). J. Hered. 2007, 98, 51-59. [CrossRef]

30. Paredes-Esquivel, C.; Donnelly, M.; Harbach, R.E.; Townson, H. A molecular phylogeny of mosquitoes in the Anopheles barbirostris Subgroup reveals cryptic species: Implications for identification of disease vectors. Mol. Phylogenet Evol. 2009, 50, 141-151. [CrossRef]

31. Coleman, A.W.; Mai, J.C. Ribosomal DNA and ITS-2 sequences comparisons as a tool for predicting genetic relatedness. J. Mol. Evol. 1997, 45, 168-177. [CrossRef]

32. Schultz, J.; Maisel, S.; Gerlach, D.; Muller, T.; Wolf, M. A common core of secondary structure of the internal transcribed spacer 2 (ITS2) throughout the Eukaryota. RNA 2005, 11, 164-361. [CrossRef]

33. Gottschling, M.; Hilger, H.H.; Wolf, M.; Diane, N. Secondary structure of the ITS1 transcript and its application in a reconstruction of the phylogeny of Boraginales. Plant Biol. 2001, 3, 629-636. [CrossRef]

34. Coleman, A.W. The Significance of a Coincidence between Evolutionary Landmarks Found in Mating Affinity and a DNA Sequence. Protist 2000, 151, 1-9. [CrossRef]

35. Coleman, A.W.; Vacquier, V. Exploring the Phylogenetic Utility of ITS Sequences for Animals: A Test Case for Abalone (Haliotis). J. Mol. Evol. 2002, 54, 246-257. [CrossRef]

36. Coleman, A.W. Pan-eukaryotic ITS2 homologies revealed by RNA secondary structure. Nucleic Acids Res. 2007, 35, 3322-3329. [CrossRef] [PubMed]

37. Muller, T.; Philippi, N.; Dandekar, T.; Schultz, J.; Wolf, M. Distinguishing species. RNA 2007, 13, 1469-1472. [CrossRef] [PubMed]

38. Coleman, A.W. Is there a molecular key to the level of "biological species" in eukaryotes? A DNA guide. Mol. Phylogenet. Evol. 2009, 50, 197-203. [CrossRef]

39. Wolf, M.; Chen, S.; Song, J.; Ankenbrand, M.; Muller, T. Compensatory base changes in ITS2 secondary structures correlate with the biological species concept despite intragenomic variability in ITS2 sequences-A proof of concept. PLoS ONE 2013, 8 . [CrossRef]

40. Wolf, M.; Selig, C.; Müller, T.; Philippi, N.; Dandekar, T.; Schultz, J. Placozoa: At least two. Biologia 2007, 62, 641-645. [CrossRef]

41. Schill, R.O.; Forster, F; Dandekar, T.; Wolf, M. Using compensatory base change analysis of internal transcribed spacer 2 secondary structures to identify three new species in Paramacrobiotus (Tardigrada). Org. Divers. Evol. 2010, 10, 287-296. [CrossRef]

42. Ruhl, M.W.; Wolf, M.; Jenkins, J.M. Compensatory base changes illuminate morphologically difficult taxonomy. Mol. Phylogenet Evol. 2010, 54, 664-669. [CrossRef] [PubMed]

43. Li, M.; Zhao, H.; Zhao, F.; Jiang, L.; Peng, H.; Zhang, W.; Simmons, M.P. Alternative analyses of compensatory base changes in an ITS2 phylogeny of Corydalis (Papaveraceae). Ann. Bot. 2019, 124, 233-243. [CrossRef] [PubMed]

44. Cai, R.; Kayal, E.; Alves-de-Souza, C.; Bigeard, E.; Corre, E.; Jeanthon, C.; Marie, D.; Porcel, B.M.; Siano, R.; Szymczak, J.; et al. Cryptic species in the parasitic Amoebophrya species complex revealed by a polyphasic approach. Sci. Rep. 2020, $10,2531$. [CrossRef] [PubMed]

45. Amato, A.; Kooistra, W.S.C.F.; Ghiron, J.H.L.; Mann, D.G.; Proschold, T.; Montresor, M. Reproductive Isolation among Sympatric Cryptic Species in Marine Diatoms. Protist 2007, 158, 193-207. [CrossRef] [PubMed]

46. Bertrand, C.; Janzen, D.H.; Hallwachs, W.; Burns, J.M.; Gibson, J.F.; Shokralla, S.; Hajibabaei, M. Mitochondrial and nuclear phylogenetic analysis with Sanger and next-generation sequencing shows that, in Área de Conservación Guanacaste, northwestern Costa Rica, the skipper butterfly named Urbanus belli (family Hesperiidae) comprises three morphologically cryptic species. BMC Evol. Biol. 2014, 14. [CrossRef]

47. Alquezar, D.E.; Hemmerter, S.; Cooper, R.D.; Beebe, N. Incomplete concerted evolution and reproductive isolation at the rDNA locus uncovers nine cryptic species within Anopheles longirostris from Papua New Guinea. BMC Evol. Biol. 2010, 10. [CrossRef]

48. Amerasinghe, F.P. A Guide to the Identification of the Anopheline Mosquitoes (Diptera: Culicidae) of Sri Lanka, I. Adult Females. Cey J. Sci. (Bio Sci.) 1990, 21, 1-16.

49. Ballinger-Crabtree, M.E.; Black IV, W.C.; Miller, B.R. Use of genetic polymorphisms detected by the Random-Amplified Polymorphic DNA Polymerase Chain Reaction (RAPD PCR) for differentiation and identification of Aedes aegypti subspecies and populations. Am. J. Trop. Med. Hyg. 1992, 47, 893-901. [CrossRef]

50. Hall, T.A. BioEdit: A user-friendly biological sequence alignment editor and analysis program for Windows 95/98/NT. In Nucleic Acid Symptoms Serials; Information Retrieval Ltd.: London, UK, 1999; Volume 41, pp. 95-98.

51. Librado, P.; Rozas, J. DnaSP v5: A software for comprehensive analysis of DNA polymorphism data. Bioinformation 2009, 25, 1451-1452. [CrossRef]

52. Sharma, D.; Issac, B.; Raghava, G.P.; Ramaswamy, R. Spectral Repeat Finder (SRF): Identification of repetitive sequences using Fourier transformation. Bioinformation 2004, 20, 1405-1412. [CrossRef]

53. Kumar, S.; Stecher, G.; Li, M.; Knyaz, C.; Tamura, K. MEGA X: Molecular Evolutionary Genetics Analysis across computing platforms. Mol. Biol. Evol. 2018, 35, 1547-1549. [CrossRef]

54. Posada, D. jModelTest: Phylogenetic model averaging. Mol. Biol. Evol. 2008, 25, 1253-1256. [CrossRef]

55. Keller, A.; Schleicher, T.; Schultz, J.; Muller, T.; Dandekar, T.; Wolf, M. 5.8S-28S rRNA interaction and HMM-based ITS2 annotation. Gene 2009, 430, 50-57. [CrossRef]

56. Reuter, J.S.; Mathews, D.H. RNAstructure: Software for RNA secondary structure prediction and analysis. BMC Bioinform. 2010, 11. [CrossRef] [PubMed] 
57. Seibel, P.N.; Müller, T.; Dandekar, T.; Schultz, J.; Wolf, M. 4SALE-A tool for synchronous RNA sequence and secondary structure alignment and editing. BMC Bioinform. 2006, 7. [CrossRef]

58. Seibel, P.N.; Müller, T.; Dandekar, T.; Wolf, M. Synchronous visual analysis and editing of RNA sequence and secondary structure alignments using 4SALE. BMC Res. Notes 2008, 1. [CrossRef] [PubMed]

59. Byun, Y.; Han, K. PseudoViewer: Web application and web service for visualizing RNA pseudoknots and secondary structures. Nucleic Acids Res. 2006, 34, W416-W422. [CrossRef] [PubMed]

60. Wolf, M.; Ruderisch, B.; Dandekar, T.; Schultz, J.; Müller, T. ProfDistS: (profile-) distance-based phylogeny on sequence—structure alignments. Bioinformation 2008, 24, 2401-2402. [CrossRef]

61. Weimers, M.; Keller, A.; Wolf, M. ITS2 secondary structure improves phylogeny estimation in a radiation of blue butterflies of the subgenus Agrodiaetus (Lepidoptera: Lycaenidae: Polyommatus). BMC Evol. Biol. 2009, 26. [CrossRef]

62. Chhilar, J.S.; Chaudhry, S. Phylogenetic Analysis of Anopheles (Cellia) subpictus Grassi using rDNA-ITS2 Sequence. Proc. Zool Soc. 2012, 65, 1-10. [CrossRef]

63. Dassanayake, R.S.; Gunawardene, Y.I.N.S.; de Silva, B.G.D.N.K. ITS-2 secondary structures and phylogeny of Anopheles culicifacies species. Bioinformation 2008, 2, 456-460. [CrossRef] [PubMed]

64. Tyagi, B.K.; Hiriyan, J.; Tewari, S.C.; Ayanar, K.; Samuel, P.P.; Arunachalam, N.; Paramasivan, R.; Krishnamoorthy, R.; Dhananjetan, K.J.; Leo, V.; et al. Description of a new species, Anopheles pseudosundaicus (Diptera: Culicidae) from Kerala, India. Zootaxa 2009, 2219, 49-60. [CrossRef]

65. Linton, Y.-M.; Harbach, R.E.; Seng, C.M.; Anthony, T.G.; Matusop, A. Morphological and molecular identity of Anopheles (Cellia) sundaicus (Diptera: Culicidae), the nominotypical member of a malaria vector species complex in Southeast Asia. Syst. Entomol. 2001, 26, 357-366. [CrossRef] 